\title{
A longitudinal study of the cultivable subgingival anaerobic bacteria isolated from sheep during the development of broken mouth periodontitis
}

\author{
J. MCCOURTIE, I. R. POXTON*, R. BROWN, C. R. WHITTAKER, J. A. SPENCE† \\ and G. U. AITCHISON†
}

\section{Department of Bacteriology, University of Edinburgh Medica/ School, Teviot Place, Edinburgh EH8 $9 A G$ and †Moredun Research Institute, 408 Gilmerton Road, Edinburgh EH17 7JH}

\begin{abstract}
Summary. In a longitudinal bacteriological study of the cultivable subgingival anaerobic flora isolated from developing broken mouth periodontitis in sheep, samples were taken from five sheep on each of three farms on seven occasions over a period of 2.5 years. Ten different bacterial genera were isolated regularly but with fluctuating frequencies. Bacteroides and Fusobacterium organisms accounted for nearly $70 \%$ of the isolates. The Bacteroides and Fusobacterium isolates studied in detail from one farm were identified to species level. The fusobacteria comprised $F$. nucleatum-like organisms $(68.6 \%)$. F . necrophorum $(29.6 \%)$ and $F$. naviforme $(1.8 \%)$. The Bacteroides spp. were divided into 11 main groups and included black-pigmented species similar to B. asaccharolyticus and B. gingivalis. On the farm studied in detail, the sheep could be allocated to two groups according to progression of periodontal disease. Most of the $B$. gingivalis-like isolates were from sheep with actively progressing disease, indicating that this organism may play a role in periodontal destruction in sheep.
\end{abstract}

\section{Introduction}

Periodontal disease (broken mouth) in sheep is in many ways similar to human periodontitis. ${ }^{1,2}$ It is a chronic inflammatory disease of the periodontium associated with alveolar bone loss which results in premature loss of the incisor teeth. The association of subgingival plaque with periodontal lesions has been shown histopathologically. ${ }^{1-3}$

Recently, several bacteriological studies in sheep have indicated the presence of anaerobic bacterial species similar to suspected periodontopathic organisms associated with periodontal disease in man. ${ }^{4-6}$ However, a study of the complete cultivable anaerobic subgingival flora of sheep has not been made. As histopathological studies show that 2-3 years elapse between the first evidence of severe gingivitis and tooth loss, ${ }^{7}$ a longitudinal study of the anaerobic flora isolated from subgingival plaque during this period may indicate the organisms that are important in periodontal disease of sheep.

The aim of this study was to perform such a longitudinal study of the subgingival flora of

Received 3 Aug. 1989; accepted 8 Sept. 1989.

*Correspondence should be sent to Dr I. R. Poxton. developing broken mouth periodontitis of sheep over a 2.5 year period and to relate the results to studies in man and other animals. A preliminary study, investigating the range of genera of anaerobic bacteria cultivable from the gingival crevices of healthy and diseased sheep ${ }^{8}$ provided information on suitable sampling procedures and cultural requirements and these methods were employed in the longitudinal study.

\section{Materials and methods}

\section{Sample collection}

From 15 flocks included in an epidemiological survey of broken mouth periodontitis in the South-east of Scotland, three flocks of Scottish Blackface sheep were selected. The flocks, on three separate farms, represented high, intermediate and low incidences of broken mouth periodontitis. Five ewes, each approximately 2.5 years old, were chosen at random from each flock at the first visit. Duplicate samples were collected by means of dental nerve broaches (Produits Dentaires S.A. Verey, Switzerland) from the same site (disto-labial site on the central right incisor) on three separate occasions throughout the year as previously described, ${ }^{8}$ for a period of 2.5 years: the first sample was examined for cultivable bacteria, the other by dark ground microscopy. 


\section{Clinical examination}

Each sheep was examined clinically and pocket depth, crown height, tooth movement, recent recession, gingivitis and occlusion were measured and scored as described by Spence and Aitchison. ${ }^{9,10}$

\section{Sample treatment}

After sampling, the dental nerve broaches were immediately placed into $0.2 \mathrm{ml}$ of pre-reduced VMGII transport medium ${ }^{11}$ under the anaerobic conditions of the Anatube Type II transport system. ${ }^{8}$ On return to the laboratory, samples were recovered inside an anaerobic cabinet (Forma Scientific, OH, USA) and diluted in prereduced $1.8-\mathrm{ml}$ volumes of nutrient broth. Samples were dispersed by repeated expression from pasteur pipettes (sheep plaque is not calcified). Volumes $(20 \mu \mathrm{l})$ of fivefold serial dilutions from $10^{1}$ to $1.56 \times 10^{5}$ were plated on to pre-reduced Gentamicin Combined Blood Agar (GCBA: Columbia agar containing horse blood 4\%, lysed blood $1 \%$, gentamicin $20 \mu \mathrm{g} / \mathrm{ml}$, haemin $5 \mu \mathrm{g} / \mathrm{ml}$ and menadione $1 \mu \mathrm{g} / \mathrm{ml}$ ). This medium has been shown to support growth of the majority of anaerobic bacterial genera commonly isolated from sheep subgingival plaque. ${ }^{8}$ Plates were incubated anaerobically in an atmosphere of $\mathrm{N}_{2} 80 \%, \mathrm{H}_{2}, 10 \%, \mathrm{CO}_{2} 10 \%$ at $37^{\circ} \mathrm{C}$ for 5 days. For total anaerobic and aerobic counts, duplicate CBA plates (GCBA plates without gentamicin) were inoculated similarly and one set was incubated anaerobically as before, while the other set was incubated aerobically at $37^{\circ} \mathrm{C}$ for 2 days.

For an accurate analysis of the bacterial composition of the samples a predetermined number of colonies was selected, in an unbiased manner, to obtain a representative cross-section of the cultivable flora. From each sample a plate containing approximately 300 colonies was chosen and placed on a grid, consisting of 192 numbered hexagons. With computer-generated random numbers, 30 colonies were subcultured from the correspondingly numbered hexagons, and plated out twice on CBA plates. One set of plates was incubated anaerobically for 2 days, or up to 4 days for slower growing organisms, while the duplicate plates were incubated aerobically. Only strictly anaerobic isolates were investigated further by gas chromatographic (GC) analysis and, where selected, for identification to species level.

\section{GC analysis}

Sample preparation. Isolates were grown in PPYG medium (proteose peptone, yeast extract medium supplemented with glucose $1 \%^{12}$ ) for 2 days, or up to 4 days for slower growing organisms. After acidification to $\mathrm{pH} 2$ or less with $\mathrm{H}_{2} \mathrm{SO}_{4} 50 \%(\mathrm{v} / \mathrm{v})$ and centrifugation, the culture supernates were extracted by a slightly modified method of Thomann and Hill, ${ }^{13}$ and analysed for volatile fatty acids (VFA) and non-volatile fatty acids (NVFA). For the VFA, $0.2 \mathrm{ml}$ of $\mathrm{H}_{2} \mathrm{SO}_{4} 50 \%, 0.4 \mathrm{~g}$ of $\mathrm{NaCl}$ and $1 \mathrm{ml}$ of methyl tert-butyl ether (MTBE) were added to $1 \mathrm{ml}$ of acidified centrifuged supernate, or to a standard mixture of VFAs. Methylation of NVFAs was achieved by overnight incubation at room temperature of $1-\mathrm{ml}$ volumes of acidified culture supernate with $0.2 \mathrm{ml}$ of $\mathrm{H}_{2} \mathrm{SO}_{4} 50 \%$ and $1 \mathrm{ml}$ of methanol; $1 \mathrm{ml}$ of water, $1 \mathrm{ml}$ of MTBE and $0.4 \mathrm{~g}$ of $\mathrm{NaCl}$ were then added. In each case the tubes were mixed mechanically for $10 \mathrm{~s}$ and allowed to stand for $10 \mathrm{~min}$ before the top MTBE layer was removed for analysis. It was not found necessary to centrifuge the samples.

GC conditions. MTBE extracts $(0.5 \mu \mathrm{l}$ volumes) were analysed isothermally at $148^{\circ} \mathrm{C}$ on a column of SP1220 $15 \%, \mathrm{H}_{3} \mathrm{PO}_{4} 1 \%$ on $100-120$ mesh Chromosorb WAW in a Perkin-Elmer 8410 gas chromatograph fitted with flame ionisation detector, integrator and AS 8300 auto-sampler.

\section{Identification schemes}

Isolates were grown initially for $24-48 \mathrm{~h}$ in PPY medium or BM-CMB (trypticase $1 \%$, proteose-peptone $1 \%$, yeast extract $0.5 \%, \mathrm{NaCl} 0.5 \%$, sodium succinate $0.25 \%)$. The $\mathrm{pH}$ was adjusted to 7.4 and menadione $(1 \mu \mathrm{g} /$ $\mathrm{ml})$, haemin $(5 \mu \mathrm{g} / \mathrm{ml})$ and L-cysteine $\mathrm{HCl}(0.075 \%)$ were added. Three volumes of this broth component were added to one volume of cooked meat particles, ${ }^{14}$ and the complete medium was sterilised by autoclaving. Cultures were diluted in pre-reduced PPY medium to just visible turbidity before $0.9-\mathrm{ml}$ inocula were added to predispensed substrates in tubes, or $30-\mu \mathrm{l}$ volumes were inoculated onto agar media for the tests listed below, and incubated anaerobically for 2 days. If growth was slow or poor, incubation was extended up to a maximum of 5 days.

Tests for Fusobacterium spp. Lipase production (on egg yolk agar); motility; aesculin hydrolysis; indole production; fermentation of glucose, lactose, sucrose, maltose, mannose, trehalose, fructose and starch. In addition, selected isolates were tested for fermentation of galactose and utilisation of lactate and threonine. ${ }^{15}$

Tests for Bacteroides spp. Pigment production (on CBA plates); gelatin digestion; motility; nitrate reduction; urease production; aesculin hydrolysis, indole production; bile tolerance; fermentation of glucose, lactose, sucrose, maltose, xylose, rhamnose, trehalose, cellobiose, xylan, aesculin, raffinose and starch.

Tests were performed as described by Brown et al. ${ }^{16}$ For fermentation tests a $\mathrm{pH}$ drop in the test substrate of greater than 0.5 units compared with the substrate-free control was considered a positive result. These tests have been successfully used in identification of clinical isolates, by comparison with results obtained with type cultures.

\section{Statistical analysis}

Spearman's rank correlation coefficients were calculated, where indicated in the text, to determine significance; the $5 \%$ level was considered significant. 
Results

In periodontal disease in sheep, the first teeth lost tend to be the central incisors. For this reason, it was decided to sample from this area only, and from as many animals as possible by limiting samples to one per sheep as the animals would have to be dropped from the study on tooth loss. Seven visits were conducted over a period of 2.5 years, with no bacteriological samples being taken at visit number four. From the 15 sheep investigated, 1908 isolates of anaerobic bacteria from the subgingival plaque were analysed by GC for VFA and NVFA end-products of metabolism.

The incidence and range of the bacterial genera isolated is shown in table $\mathrm{I}$, in descending order of prevalence. The majority of isolates were Bacteroides or Fusobacterium spp., comprising $49.2 \%$ and $17.5 \%$ respectively of the total number. Aerobic or facultative organisms comprised $10.3 \%$ of the total number of isolates, while $7.9 \%$ were unidentified either because they could not be recovered by subculture from the original isolate, or the GC profiles were not recognised. The incidence of most of the bacterial genera remained fairly constant, with only slight fluctuations, over the period of the longitudinal study. There were no significant differences in the types of organisms isolated from the flocks representing high, medium and low incidences of broken mouth periodontitis. There were significant negative correlations between the proportions of isolates that were Lactobacillus, aerobic organisms, and the combination of the less commonly isolated genera on the one hand and the visit number on the other. The latter group of less common genera comprised Actinomyces, Propionibacterium, Leptotrichia and Bifidobacterium; these were analysed cumulatively because their individual numbers were too low to test.

As the Bacteroides and Fusobacterium spp. accounted for nearly $70 \%$ of the organisms isolated, these were identified further by a series of biochemical and fermentation tests. Because some sheep were lost or removed from two of the farms for veterinary reasons, the remaining farm was selected for this part of the study: this one had an intermediate broken mouth problem and complete records.

The Fusobacterium isolates could be divided into three species- $F$. nucleatum-like $(68.6 \%), F$. necrophorum $(29.6 \%)$ and $F$. naviforme $(1.8 \%)$. However, the $F$. nucleatum-like isolates were unusual in that most of them fermented glucose and fructose more strongly than would be expected. This suggested that they may be more like the oral isolates obtained from monkeys, $F$. simiae, ${ }^{17}$ or from man, $F$. periodonticum. ${ }^{18}$ To try to verify this, 12 selected isolates were further tested for fermentation of galactose and utilisation of lactate and threonine (indicated by an increase in the production of propionate in the VFA GC profile when lactate or threonine is present in the growth medium). None of these isolates fermented galactose and was, therefore, not $F$. periodonticum. However, of the isolates tested, most utilised threonine and lactate to varying extents, indicating the possibility that they are more like the monkey isolate, $F$. simiae. As there are no clear cut definitions for interpretation of the tests for utilisation of lactate and threonine, ${ }^{19}$ it was difficult to distinguish between $F$. nucleatum

Table I. Incidence and range of bacterial genera isolated from samples obtained from visits to three farms

\begin{tabular}{|c|c|c|c|c|c|c|c|c|}
\hline \multirow[b]{2}{*}{ Genus or group } & \multicolumn{6}{|c|}{$\begin{array}{c}\text { Percentage of isolates representing each genus at } \\
\text { visit no. }\end{array}$} & \multirow{2}{*}{$\begin{array}{c}\text { Total } \\
\text { numbers of } \\
\text { isolates }\end{array}$} & \multirow{2}{*}{$\begin{array}{l}\text { Percentage of } \\
\text { all isolates }\end{array}$} \\
\hline & 1 & 2 & 3 & 5 & 6 & 7 & & \\
\hline Bacteroides & $37 \cdot 7$ & $45 \cdot 7$ & $54 \cdot 7$ & $59 \cdot 3$ & $44 \cdot 8$ & $52 \cdot 7$ & 1047 & $49 \cdot 2$ \\
\hline Fusobacterium & $21 \cdot 7$ & $7 \cdot 7$ & $10 \cdot 2$ & $13 \cdot 0$ & $26 \cdot 7$ & $33 \cdot 0$ & 373 & $17 \cdot 5$ \\
\hline Lactobacillus & $8 \cdot 6$ & $10 \cdot 0$ & $3 \cdot 3$ & 0.7 & $1 \cdot 1$ & $0 \cdot 3$ & 94 & $4 \cdot 4$ \\
\hline Clostridium & $1 \cdot 2$ & $5 \cdot 5$ & $5 \cdot 6$ & $4 \cdot 3$ & 5.9 & 0.9 & 85 & $4 \cdot 0$ \\
\hline Anaerobic cocci & 3.9 & $3 \cdot 2$ & $3 \cdot 3$ & $5 \cdot 0$ & $3 \cdot 0$ & $2 \cdot 4$ & 73 & $3 \cdot 5$ \\
\hline Eubacterium & 0 & $6 \cdot 4$ & $1 \cdot 6$ & $2 \cdot 7$ & $2 \cdot 2$ & 0 & 49 & $2 \cdot 3$ \\
\hline Actinomyces & 0 & $1 \cdot 6$ & $0 \cdot 4$ & 0 & 0 & 0 & 9 & 0.4 \\
\hline Propionibacterium & 0.9 & 0.5 & 0 & 0 & 0 & 0 & 5 & $0 \cdot 2$ \\
\hline Leptotrichia & 0 & $0 \cdot 2$ & $0 \cdot 2$ & 0 & 0.4 & 0 & 3 & $0 \cdot 1$ \\
\hline Bifidobacterium & $0 \cdot 3$ & $0 \cdot 2$ & 0 & 0 & 0 & 0 & 2 & $0 \cdot 1$ \\
\hline Unidentified & $11 \cdot 3$ & $4 \cdot 5$ & $10 \cdot 0$ & $2 \cdot 3$ & $10 \cdot 7$ & $8 \cdot 8$ & 168 & 7.9 \\
\hline Aerobes & $14 \cdot 5$ & $14 \cdot 5$ & $10 \cdot 7$ & $12 \cdot 7$ & $5 \cdot 2$ & $1 \cdot 8$ & 219 & $10 \cdot 3$ \\
\hline
\end{tabular}


and $F$. simiae by these criteria; for the purpose of this study we have defined these isolates as $F$. nucleatum-like.

The Bacteroides isolates were placed in groups according to their biochemical characteristics. Any group with fewer than five members, or in which the majority of the members were isolated from one subgingival plaque sample, were discounted. Eleven groups were obtained, which are outlined in table II.

It was difficult to assign the Bacteroides isolates to the currently recognised species. Groups $1,3,5$ and 6 bear little resemblance to any described Bacteroides species, and possibly represent new (sheep-specific) species. Group 2 is similar to $B$. oris or $B$. buccae, whereas Group 7 resembles $B$. disiens. The asaccharolytic isolates, groups 8-11, could be described as $B$. asaccharolyticus-like, $B$. nodosus-like, B. capillosus-like and B. gingivalis-like, respectively.

The proportions of each Bacteroides group and
Fusobacterium sp. isolated at each farm visit are shown in table III. The incidence of most of the Bacteroides groups fluctuated between visits. However, on examination of the overall trends, isolates in groups $3,5,6,7,8$ and 11 appeared to increase in number as the study progressed. The numbers of $F$. nucleatum-like isolates were very variable but the numbers of $F$. necrophorum decreased with time. No statistical analysis of these results was made as the numbers of isolates involved at many of the sampling times were too low to give a statistically representative sample.

The degree of gingival inflammation, recorded at each farm visit, is represented by the gingivitis index (GI; fig. 1a); the pocket indices (PI) are shown in fig. $1 \mathrm{~b}$. During the period of the longitudinal bacteriological study (visits $1-7$ ) the GI and PI rose steadily in two of the sheep (nos. 1 and 2) while the other three sheep showed more fluctuation and lower values.

The periodontal health of the sheep can be

Table II. Biochemical characteristics of the Bacteroides spp. isolated from sheep on the farm with an intermediate incidence of broken mouth periodontitis

\begin{tabular}{|c|c|c|c|c|c|c|c|c|c|c|c|}
\hline \multirow[b]{2}{*}{ Characteristic } & \multicolumn{11}{|c|}{ Reaction of group no. } \\
\hline & 1 & 2 & 3 & 4 & 5 & 6 & 7 & 8 & 9 & 10 & 11 \\
\hline Pigment production & - & - & - & - & - & - & - & + & - & - & + \\
\hline Gelatin hydrolysis & + & - & $-(+)$ & $+1-$ & + & - & $+1-$ & $+1-$ & $+1-$ & $-(+)$ & + \\
\hline Nitrate reduction & - & - & - & - & - & - & - & - & - & - & - \\
\hline Urease production & - & - & - & - & - & - & - & - & - & - & - \\
\hline Aesculin hydrolysis & - & + & $+(-)$ & $-(+)$ & + & - & $+1-$ & - & - & + & - \\
\hline Indole production & - & - & + & - & - & - & - & $+1-$ & - & - & + \\
\hline Bile tolerance & - & - & - & - & - & - & - & - & - & - & - \\
\hline \multicolumn{12}{|l|}{ Fermentation of: } \\
\hline glucose & + & + & + & + & + & + & + & - & - & - & - \\
\hline lactose & + & + & + & + & - & - & - & - & - & - & - \\
\hline sucrose & - & + & + & + & $+1-$ & + & - & - & - & - & - \\
\hline maltose & - & + & + & + & $+(-)$ & + & $+(-)$ & - & - & - & - \\
\hline xylose & - & + & - & - & - & - & - & - & - & - & - \\
\hline rhamnose & - & $+(-)$ & - & - & - & - & - & - & - & - & - \\
\hline trehalose & - & - & - & - & - & - & - & - & - & - & - \\
\hline cellobiose & - & + & $-(+)$ & - & + & - & - & - & - & - & - \\
\hline xylan & - & $+1-$ & - & - & - & - & - & - & - & - & - \\
\hline aesculin & - & $+1-$ & $-(+)$ & $+1-$ & $-(+)$ & - & - & - & - & - & - \\
\hline raffinose & - & + & + & $+(-)$ & $+1-$ & $-(+)$ & - & - & - & - & - \\
\hline starch & - & + & + & + & + & + & + & - & - & - & - \\
\hline GC profile & $\begin{array}{l}\text { aPib } \\
\text { ivLs }\end{array}$ & apLs & $\begin{array}{l}\text { apls } \\
\text { (iv) }\end{array}$ & $\begin{array}{l}\text { apls } \\
\text { (iv) }\end{array}$ & $\begin{array}{c}\text { als } \\
\text { (pibiv) }\end{array}$ & $\begin{array}{l}\text { als } \\
\text { (iv) }\end{array}$ & $\begin{array}{l}\text { alS } \\
\text { (iv) }\end{array}$ & $\begin{array}{c}\text { apibb } \\
\text { ivls }\end{array}$ & $\begin{array}{l}\text { as (pib } \\
\text { ivls) }\end{array}$ & $\begin{array}{l}\text { as (pib } \\
\text { ivl) }\end{array}$ & $\begin{array}{l}\text { apbiv } \\
\text { sph(1) }\end{array}$ \\
\hline Number of isolates & 60 & 47 & 35 & 13 & 27 & 13 & 23 & 39 & 27 & 9 & 22 \\
\hline
\end{tabular}

,$+>90 \%$ of strains positive $;-,>90 \%$ of strains negative $;+/-, 30-70 \%$ of strains gave each result $;+(-)$ or $-(+), 70-90 \%$ of strains gave the first result.

a, Acetic acid; P/p, propionic acid; ib, isobutyric acid; b, butyric acid; iv, isovaleric acid; ph, phenylacetic acid; L/l, lactic acid; and $S / \mathrm{s}$, succinic acid. Upper case letters; $\geqslant 10 \mathrm{mmol} / \mathrm{L}$; lower case letters, $0 \cdot 2-9 \cdot 9 \mathrm{mmol} / \mathrm{L}$. Letters in parenthesis represent variable production. 
Table III. Distribution of Bacteroides and Fusobacterium spp. isolated from sheep on a farm with an intermediate incidence of broken mouth periodontitis

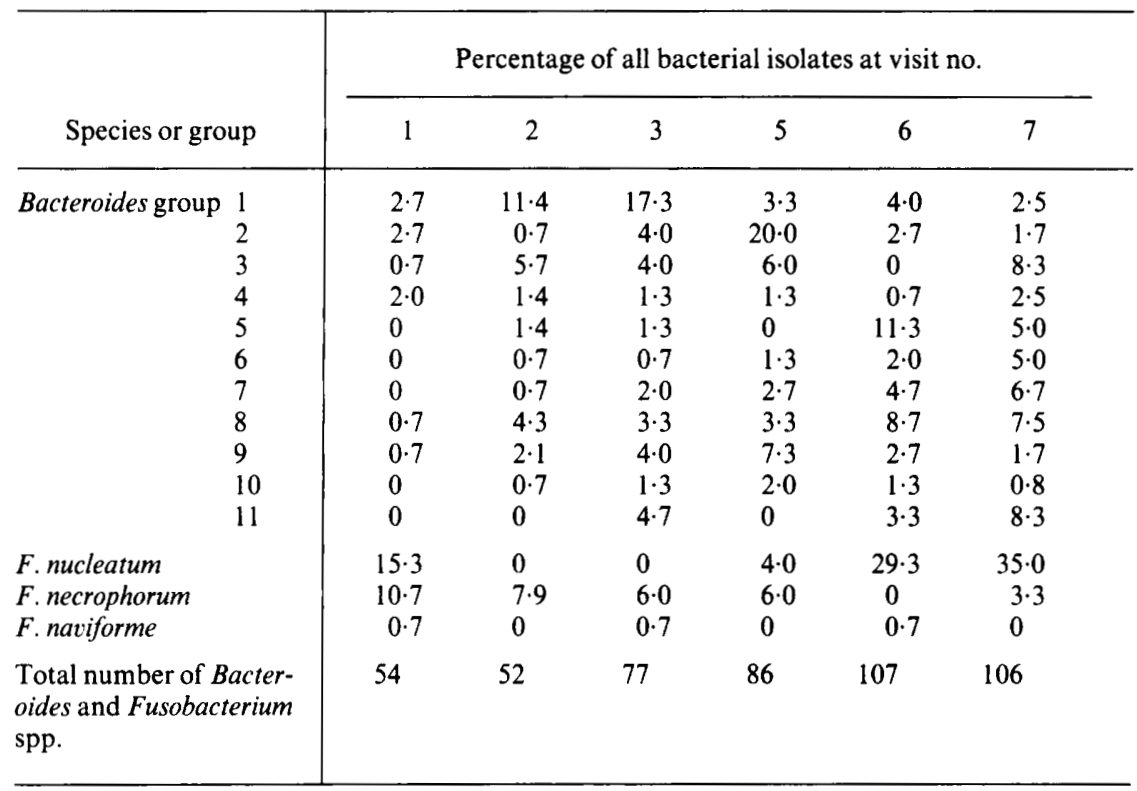

assessed by the dental index (DI: fig. 2), which represents the average of the indices for pocket depth, gingival inflammation, gum recession and tooth displacement measurements. Our previous experience has shown that a DI of greater than 10 predisposes to tooth loss. Two of the sheep (nos. 1 and 2) had rapidly increasing DI; sheep 2 had lost one central incisor at visit 7 (age 5 years) and sheep 1 had lost the central and second incisors by the end of the study (age 5 years). The other three sheep (nos. 3-5) appeared to have a more slowly progressing condition.

Unfortunately, we cannot compare the clinical status of the sampled sites in relation to their bacteriology because the samples were taken from sites distinct from the clinically monitored sites. This was to avoid any possible periodontal damage or bacteriological changes that may be caused by repeated probing for measurement of indices. However, pocket depths at the sampling sites were recorded and these followed the same trends as the overall pocket indices shown in fig. $1 \mathrm{~b}$.

When the Bacteroides and Fusobacterium isolates were compared, according to the periodontal status of the sheep from which they were isolated, only Bacteroides group 11, which consisted of the $B$. gingivalis-like isolates showed any differences (table IV). The majority of $B$. gingivalis-like organisms were isolated from the subgingival plaque of sheep with active broken mouth periodontitis (high dental indices); only one isolate of this type was from the sheep with a slowly progressing condition (low dental indices), and that was isolated during the last visit.

\section{Discussion}

The range of genera isolated in this study was similar to that obtained in a preliminary study of the anaerobic bacteria isolated from the subgingival plaque from sheep, ${ }^{8}$ except that no Veillonella spp. were recovered as a Veillonella selective medium was not used. The incidence of Eubacterium spp. was higher than found previously, although this was mainly due to a high incidence of this genus in one single plaque sample. Capnocytophaga and Eikenella spp. have also been isolated in low numbers from subgingival plaque of sheep $^{6}$ but

Table IV. Distribution of B. gingivalis-like isolates (Group 11) from sheep with high and low final cumulative dental indices

\begin{tabular}{l|ccccccc}
\hline & \multicolumn{6}{|c}{$\begin{array}{c}\text { Percentage of total bacteria isolated at } \\
\text { visit no. }\end{array}$} \\
\cline { 2 - 7 } Dental index* & 1 & 2 & 3 & 5 & 6 & 7 \\
\hline High & 0 & 0 & 11.7 & 0 & $8 \cdot 3$ & 15.0 \\
Low & 0 & 0 & 0 & 0 & 0 & 1.7 \\
\hline
\end{tabular}

* Dental index was considered high when the final cumulative dental index was $\geqslant 10$ and low when $<10$ (see fig. 2). Data are for the animals included in figs. 1 and 2. 


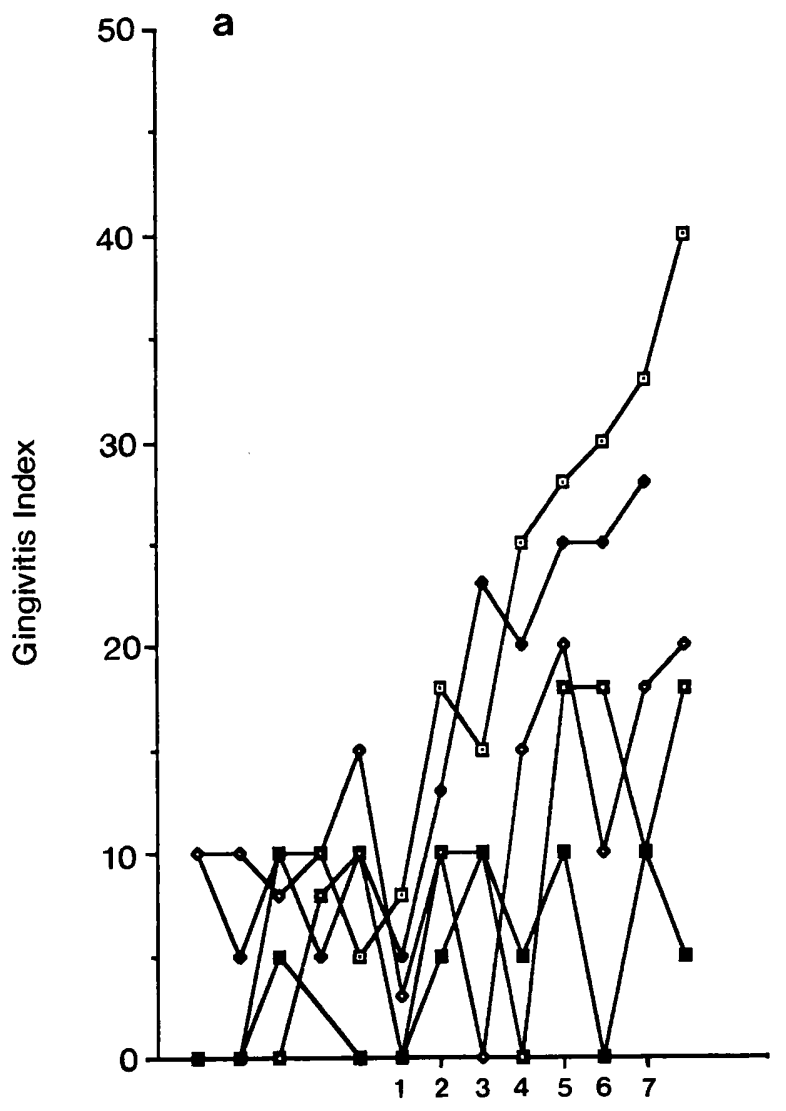

Visit number

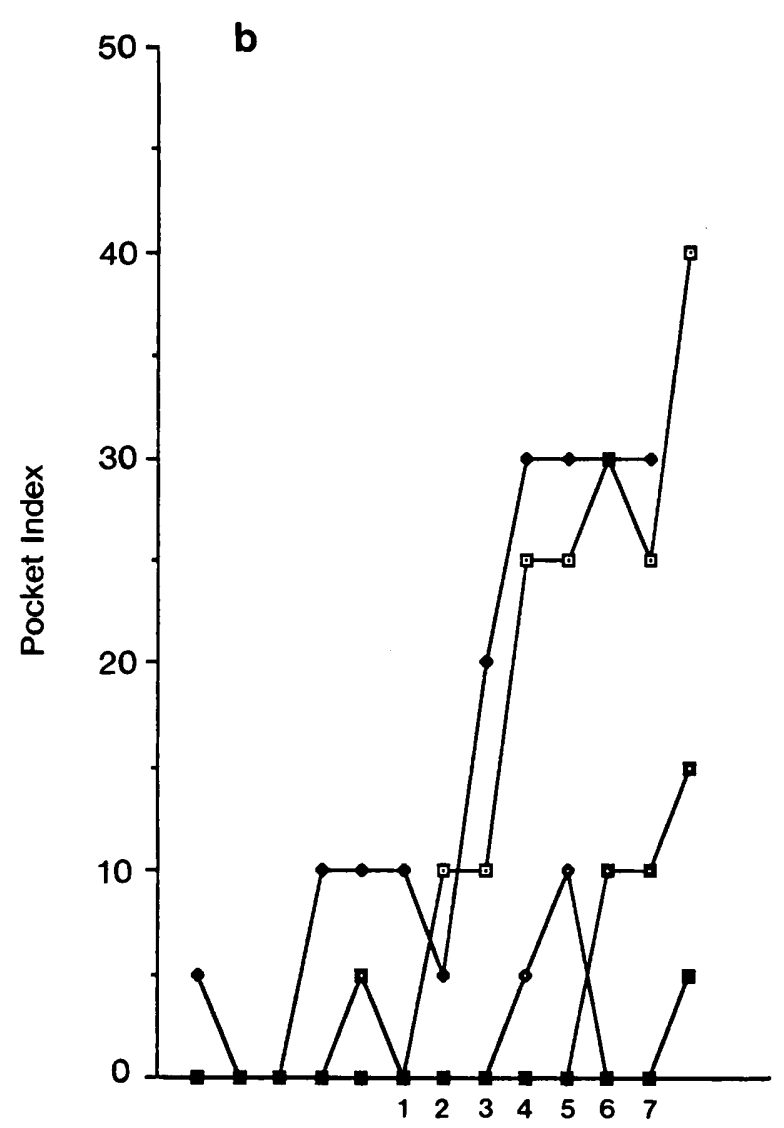

Visit number

Fig. 1. Changes in (a) gingivitis indices and (b) pocket indices in five sheep with sequential visits to a farm with an intermediate incidence of broken mouth periodontitis, over a period of 4.5 years. Bacteriological samples were taken at visits 1-7, over a period of 2.5 years. Sheep $1-\square$; sheep $2 \multimap$; sheep $3-$; sheep $4 \multimap$; sheep $5-$

these organisms were not found in this study. The incidence of each of the more commonly isolated genera or groups (Bacteroides, Fusobacterium, Clostridium, anaerobic cocci and Eubacterium) remained relatively stable over the period of the longitudinal study. Only Lactobacillus spp. and the less commonly isolated genera were seen to reduce in numbers over the 2.5 year project.

The three farms used were chosen initially for the different records of periodontal disease so that a range of periodontal conditions could be covered throughout the longitudinal study. However, the sheep used on each individual farm gave a range of periodontal disease involvement. In the farm chosen for detailed study of the Fusobacterium and Bacteroides isolates, two of the sheep had rapidly progressive periodontitis culminating in tooth loss, while the dentition of the other three remained relatively healthy over the $2 \cdot 5$ year study.
The dental health indices (GI, PI and DI) and incidences of bacterial genera and bacterial groups fluctuated considerably during the study. This confirmed the results obtained in a year-long study of the clinical development of broken mouth in a single flock of sheep ${ }^{10}$ and could reflect the episodic nature thought to occur with periodontitis in $\operatorname{man}^{20.21}$ and in sheep. ${ }^{22}$ Broken mouth periodontitis in sheep has also been shown to have seasonal variation $^{23}$ and may be affected by nutritional and environmental factors. ${ }^{10}$ The sheep used in this study were hill sheep, and only readily available for sampling three times a year. There was no control over environmental factors, and diets may have varied, due to increased feeding of pregnant ewes, especially those expected to produce twins.

Fusobacterium spp. are found commonly in human subgingival plaque, and $F$. nucleatum is the most frequently detected species. ${ }^{24}$ This species is 


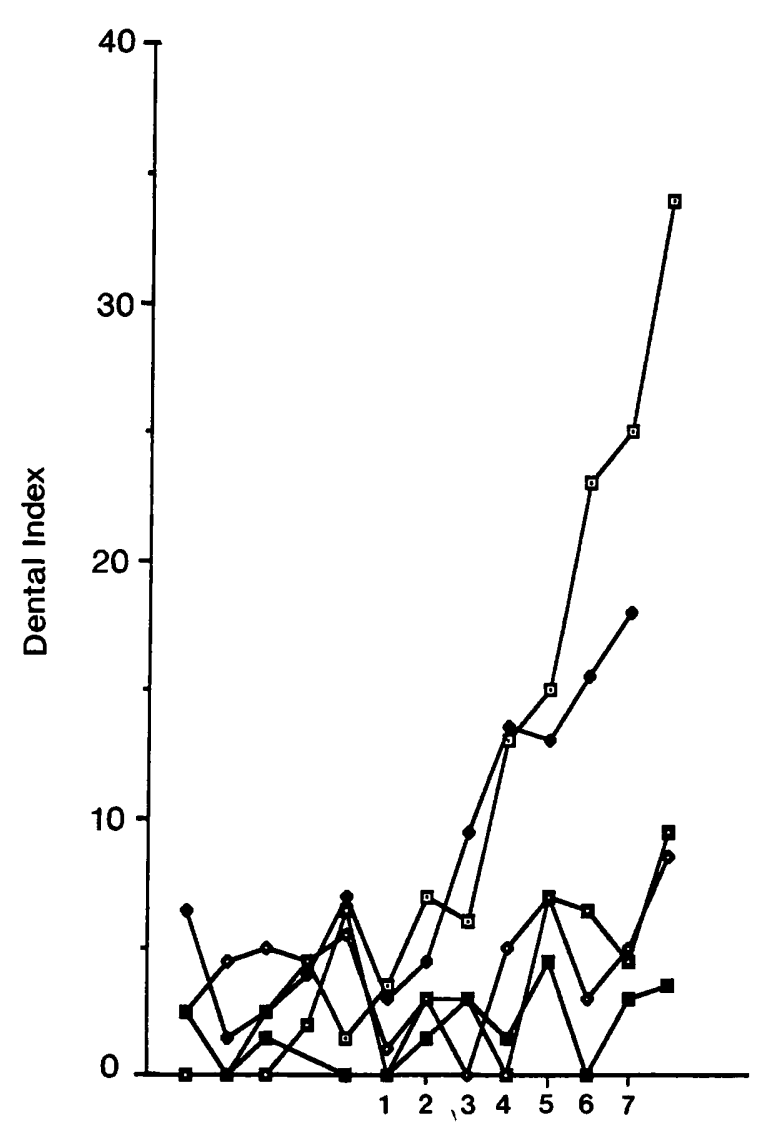

Visit number

Fig. 2. Changes in dental indices in five sheep with sequential visits to a farm with an intermediate incidence of broken mouth periodontitis, over a period of 4.5 years. Bacteriological samples were taken at visits $1-7$, over a period of 2.5 years. Sheep $1-\square-$; sheep $2 \dashv$; sheep $3-$; sheep $4-$; sheep $5-$

associated with both active and inactive periodontal sites in $\operatorname{man}^{25,26}$ and it is thought that this might indicate a heterogeneity within the species. ${ }^{24}$ Similarly, in this study there was no difference in the incidence of $F$. nucleatum-like isolates between the two categories of periodontal status described.

The Fusobacterium isolates from sheep comprised three species biochemically similar to the human types. However, further examination of selected organisms from the $F$. nucleatum-like group indicated that some of these may be $F$. simiae. These two species have been shown to be closely related by DNA homology studies. ${ }^{27}$ Clearly the isolates from sheep merit a more detailed investigation.

In a bacteriological study with sheep allocated to three groups according to degree of periodontal destruction, $F$. necrophorum and $F$. nucleatum were found commonly. ${ }^{6}$ In addition, $F$. nucleatum Type II (separated from Type I by colony morphology on selective medium) ${ }^{28}$ correlated with disease severity. Indeed, a statistically significant increase in Type II isolates with increasing levels of gingivitis in human periodontal disease has been demonstrated ${ }^{29}$ although the two types appeared to be identical by double diffusion in agar and similarity of polyacrylamide gel electrophoresis protein patterns. In the study presented here, it was difficult to distinguish between colony types (results not shown) and, because of the possibility that some of the isolates might have been $F$. simiae, this was not investigated further.

A study of Fusobacterium spp. isolated from bite wounds in cats indicated that $F$. russii predominates in the oral Fusobacterium population with smaller amounts of $F$. necrophorum, $F$. naviforme (found in low numbers in this study) and $F$. nucleatum being isolated. ${ }^{19}$ Those isolated were shown to be genetically distinct from human oral strains. ${ }^{30}$

In studies of human periodontitis, spirochaetes have been found more frequently and in higher numbers in diseased sites compared with healthy sites. ${ }^{31}$ Spirochaetes were observed in all plaque samples in this study by dark ground microscopy, and also in other studies. ${ }^{10,32}$ Our attempts to grow sheep spirochaetes (not reported here) were largely unsuccessful. However, spirochaetes from monkey periodontal pockets have been shown to have different nutritional requirements from human isolates $^{33}$ and this may account for the lack of success in this study.

Many of the Bacteroides spp. isolated in this study were very fastidious, and grew poorly in pure culture on solid media. In many cases growth was enhanced by deliberately seeding the agar media, close to the Bacteroides inoculum, with an aerobic organism. Growth was enhanced near to the stimulating organisms, particularly with the blackpigmented Bacteroides where pigment production was just detected at the opposing edge. This implies that these isolates require additional nutrients not present in the media, and may be indicative of the dissimilarity of these isolates from human strains.

The sheep Bacteroides isolates could be placed in 11 broad categories by the tests used in this study. Groups 1, 3, 5, and 6 are likely to be new species of Bacteroides. However, a full characterisation of these isolates with guanine plus cytosine content of the DNA and DNA-DNA homology studies would have to be performed to confirm this. Under certain growth conditions a small proportion of the cells of two isolates of Group 4 were motile and this merits further investigation. Group 7 was like B. disiens. 
Although this organism is commonly isolated from the vaginal flora, it has also been recognised as a common anaerobic isolate from bite-wound infections. ${ }^{34}$

Although the isolation frequency of several groups of Bacteroides spp. and $F$. nucleatum-like organisms increased during the study, only the $B$. gingivalis-like isolates appeared to be associated with active periodontal disease. No statistical analysis was carried out on these data as the large number of zero values made this difficult, and the number of sheep in the groups (two in the high index group and three in the low index group) was considered too low to provide significant results.

Frisken et al. ${ }^{5,6}$ have also shown increased incidence of total black-pigmented Bacteroides species and, in particular, $B$. gingivalis in periodontally affected sheep. However, the incidence of $B$. gingivalis-like organisms was much lower than that found in this study (up to $15 \%$ of the total number of anaerobes in periodontally affected sheep) and differences were not statistically significant. This difference could be due to the longitudinal nature of this study, with increased chances of sampling during active episodes of disease progression, or to the use of different isolation media.

\section{REFERENCES}

1. Cutress $T$ W. Histopathology of periodontal disease in sheep. J Periodontol 1976; 47: 643-650.

2. Spence J A, Aitchison G U, Sykes A R, Atkinson P J. Broken mouth (premature incisor loss) in sheep: the pathogenesis of periodontal disease. J Comp Pathol 1980; $90: 275-292$.

3. Dreyer W P, Austin J C, Schneider D J, Viljoen J H. Periodontal disease in sheep in the Western Cape. $J$ Dent Res 1982; 61: 604. Abstract no. 17.

4. Dreyer W P, Parker J R, Ebersole J L et al. The bacteriology of sheep periodontitis with special reference to Actinobacillus actinomycetemcomitans. Tydskr Tandheelkd Ver $S$ Afr 1986; 41 : 229-233.

5. Frisken K W, Tagg J R, Laws A J, Orr M B. Blackpigmented Bacteroides associated with broken-mouth periodontitis in sheep. $J$ Periodont Res 1987; 22: 156159.

6. Frisken K W, Tagg J R, Laws A J, Orr M B. Suspected periodontopathic bacteria associated with brokenmouth periodontitis in sheep. J Periodont Res 1988; 23 : 18-21.

7. Spence J A. Studies into the pathogenesis of early tooth loss (broken mouth) in sheep. Fellowship Thesis, Royal College of Veterinary Surgeons, London. 1982.

8. McCourtie J, Poxton I R, Spence J A, Aitchison G U. Preliminary study of the anaerobic bacteria isolated from subgingival plaque from sheep. Vet Microbiol $1989 ; 21: 139-146$.

9. Spence J, Aitchison G. Clinical aspects of dental disease in sheep. In Practice, suppl to Vet Rec 1986; 8: 128-135.
B. gingivalis is commonly thought to be an important periodontopathic component in periodontitis of man, and a correlation between degree of inflammation and quantity of $B$. gingivalis in subgingival plaque has been shown. ${ }^{35,36}$ Thought to be the most virulent of the black-pigmented Bacteroides, ${ }^{37}$ B. gingivalis has extensive proteolytic properties $^{38}$ and its lipopolysaccharide, although low in toxicity, has been shown to mediate bone resorption in vitro ${ }^{39}$ and in vivo. ${ }^{40}$ Isolates from sheep have been shown to have enzyme activities similar to human isolates, including a trypsin-like activity. ${ }^{41}$ Oral $B$. gingivalis-like isolates have been described in other animals-cats, dogs, raccoons, jaguars and squirrel monkeys. ${ }^{42-44}$ From our study, $B$. gingivalis-like isolates appear also to play a role in broken mouth in sheep.

The results of this study indicate some similarities and also some differences in the periodontal flora of man and sheep. This merits further investigation, with more animals, and further characterisation of the isolates obtained.

This work was funded by the Wellcome Trust (Grant No. 14552/1.5). We are extremely grateful to $\mathrm{Mr} \mathrm{K}$. Miller for arranging the farm visits.

10. Spence J A, Aitchison G U, Fraser J. Development of periodontal disease in a single flock of sheep: clinical signs, morphology of subgingival plaque and influence of antimicrobial agents. Res Vet Sci 1988; 45: 324-331.

11. Holbrook W P, Ogston S A, Ross P W. A method for the isolation of Bacteroides melaninogenicus from the human mouth. J Med Microbiol 1978; 11 : 203-207.

12. Deacon A G, Duerden B I, Holbrook W P. Gas-liquid chromatographic analysis of metabolic products in the identification of Bacteroidaceae of clinical interest. $J$ Med Microbiol 1978; 11 : 81-99.

13. Thomann W R, Hill G B. Modified extraction procedure for gas-liquid chromatography applied to the identifcation of anaerobic bacteria. J Clin Microbiol 1986; 23 : 392-394.

14. Collee J G, Marr W. Culture containers and culture media. In : Collee J G, Duguid J P, Fraser A G, Marmion B P (eds) Mackie and McCartney: Practical medical microbiology, Vol 2, 13th edn. Edinburgh, Churchill Livingstone. $1989: 114$.

15. Holdeman L V, Cato E P, Moore W E C. Anaerobe laboratory manual, 4th edn. Blacksburg, Virginia Polytechnic Institute and State University. 1977.

16. Brown R, Collee J G, Poxton I R, Fraser A G. Bacteroides, Fusobacterium and related organisms : anaerobic cocci: identification of anaerobes. In: Collee J G, Duguid J P, Fraser A G, Marmion B P (eds) Mackie and McCartney: Practical medical microbiology, vol 2, 13th edn. Edinburgh, Churchill Livingstone. 1989: 553-570.

17. Slots J, Potts T V. Fusobacterium simiae, a new species from 
monkey dental plaque. Int J Systemat Bacteriol 1982; 32: 191-194.

18. Slots J, Potts T V, Mashimo P A. Fusobacterium periodonticum, a new species from the human oral cavity. $J$ Dent Res 1983; 62: 960-963.

19. Love D N, Jones R F, Bailey M. Characterization of Fusobacterium species isolated from soft tissue infections in cats. $J$ Appl Bacteriol 1980; 48 : 325-331.

20. Goodson J M, Tanner A C R, Haffajee A D, Sornberger G $\mathrm{C}$, Socransky S S. Patterns of progression and regression of advanced destructive periodontal disease. $J$ Clin Periodontol 1982: 9: 472-481.

21. Listgarten M A. Pathogenesis of periodontitis. J Clin Periodontol 1986; 13: 418-430.

22. Laws A J, Frisken K W, Orr M B. A study of periodontal disease in sheep over a twelve month period. NZ Vet $J$ $1988 ; 36: 32-34$.

23. Armstrong M C. Paradontal disease of sheep in South Canterbury. Preliminary report on investigations. $N Z$ J Agric 1960; 100 : 429-431.

24. Dzink J L, Socransky S S, Haffajee A D. The predominant cultivable microbiota of active and inactive lesions of destructive periodontal diseases. J Clin Periodontol $1988 ; 15: 316-323$.

25. Dzink J L, Tanner A C R, Haffajee A D, Socransky S S. Gram negative species associated with active destructive periodontal lesions. $J$ Clin Periodontol 1985; 12: 648-659.

26. Moore W E C. Microbiology of periodontal disease. $J$ Periodont Res 1987; 22: 335-341.

27. Potts T V, Holdeman L V, Slots J. Relationships among the oral fusobacteria assessed by DNA-DNA hybridization. $J$ Dent Res 1983; 62: 702-705.

28. Walker C B, Ratliff D, Muller D, Mandell R, Socransky S S. Medium for selective isolation of Fusobacterium nucleatum from human periodontal pockets. $J$ Clin Microbiol 1979; 10: 844-849.

29. Vincent J W, Cornett W C, Falkler W A, Montoya R G. Biologic activity of type I and type II Fusobacterium nucleatum isolates from clinically characterized sites. $J$ Periodontol $1985 ;$ 56: 334-339.

30. Love D N, Cato E P, Johnson J L, Jones R F, Bailey M. Deoxyribonucleic acid hybridization among strains of fusobacteria isolated from soft tissue infections of cats: comparison with human and animal type strains from oral and other sites. Int J Systemat Bacteriol 1987; 37: 23-26.

31. Armitage G C, Dickinson W R, Jenderseck R S, Levine S $\mathrm{M}$, Chambers D W. Relationship between the percent- age of subgingival spirochetes and the severity of periodontal disease. J Periodontol 1982; 53 : 550-556.

32. Salisbury R M, Armstrong M C, Gray K G. Ulceromembranous gingivitis in the sheep. NZ Vet J 1953; 1 : 51-52.

33. Sela $\mathbf{M}$, Kornman $\mathrm{K}$ S, Holt S C. Characterization of spirochetes isolated from human and primate periodontal pockets. J Dent Res $1986 ; 65: 816$. Abstract no. 815 .

34. Goldstein E J C, Citron D M, Finegold S M. Role of anaerobic bacteria in bite-wound infections. Rev Infect Dis 1984; 6 Suppl 1: S177-S183.

35. Tanner A C R, Haffer C, Bratthall G T, Visconti R A, Socransky S S. A study of the bacteria associated with advancing periodontitis in man. $J$ Clin Periodontol $1979 ; 6: 278-307$.

36. White D, Mayrand D. Association of oral Bacteroides with gingivitis and adult periodontitis. J Periodont Res 1981 ; 16: $259-265$.

37. van Steenbergen T J M, Kastelein P, Touw J J A, de Graaff J. 'Virulence of black-pigmented Bacteroides strains from periodontal pockets and other sites in experimentally induced skin lesions in mice. J Periodont Res 1982; 17: 41-49.

38. van Winkelhoff $\mathbf{A} \mathbf{J}$, van Steenbergen $\mathbf{T} \mathbf{J} \mathbf{M}$, de Graaff $\mathbf{J}$. The role of black-pigmented Bacteroides in human oral infections. J Clin Periodontol 1988; 15 : 145-155.

39. Sismey-Durrant H J, Hopps R M. The effect of lipopolysaccharide from the oral bacterium Bacteroides gingivalis on osteoclastic resorption of sperm-whale dentine slices in vitro. Arch Oral Biol 1987; 32: 911-913.

40. Roeterink C H, van Steenbergen T J M, de Jong W F B, de Graaff J. Histopathological effects in the palate of the rat induced by ingestion with different black-pigmented Bacteroides strains. J Periodont Res 1984; 19:292-302.

41. Frisken K W, Laws A J, Tagg J R, Orr M B. The characterization of trypsin-positive black-pigmented Bacteroides isolated from sheep periodontal disease. Lett Appl Microbiol 1986; 3: 57-60.

42. Laliberte M, Mayrand D. Characterization of blackpigmented Bacteroides strains isolated from animals. $J$ Appl Bacteriol 1983; 55: 247-252.

43. Mikx F H M, Hug H U, Maltha J C. Necrotizing ulcerative gingivitis in beagle dogs. I. Attempts at unilateral induction and intraoral transmission of NUG, a microbiological and clinical study. $J$ Periodont Res 1984; 19: 76-88.

44. Clark W B, Magnussen I, Abee C, Collins B, Beem J E, McArthur W P. Natural occurrence of black-pigmented Bacteroides species in the gingival crevice of the squirrel monkey. Infect Immun 1988; 56: 2392-2399. 